\title{
LIPOPOLYSACCHARIDE BASED INDIRECT ELISA FOR RAPID DETECTION OF PASTEURELLA MULTOCIDA ANTIBODIES IN BOVINES
}

\author{
M. ANIL ${ }^{1}$, P. NAVANEETHA ${ }^{1}$, P.V. JANARDHAN REDDY ${ }^{2}$, \\ A.VIJAYAKUMAR ${ }^{3}$ AND P. RATHNAGIRI ${ }^{* 4}$
}

${ }^{1}$ Department of Medical Microbiology, Genomix Molecular Diagnostics Pvt. Ltd., Hyderabad- 500 072, Telangana, India

${ }^{2}$ Department of Veterinary Microbiology, Genomix CARL Pvt. Ltd., Pulivendula - 516390, Andhra Pradesh, India

${ }^{3}$ Department of Veterinary Public Health and Epidemiology, College of Veterinary Science, Rajendranagar, PVNR Telangana Veterinary University, Hyderabad-30

${ }^{4}$ Genomix Group of Companies, USA \& India

\begin{abstract}
Haemorrhagic septicaemia is an important economic disease of bovines caused by Pasteurella multocida which is one of the major causes of livestock mortality in tropical regions of Asia. There is no reliable serological assay for distinct diagnosis of the disease. The aim of the present study is to develop an indirect ELISA (iELISA) assay for the detection of antibodies against $P$. multocida in cattle and buffaloes. To develop these assay lipopolysaccharide of $P$. multocida serotype B:2 used as antigen. The lipopolysaccharide (LPS) of $P$. multocida was characterized by silver stained sodium dodecyl sulphatepolyacrylamide gel electrophoresis (SDS-PAGE). A total of three hundred seventy three different field sera samples were collected. Using known negative and positive serum samples, it was found that LPS based indirect ELISA for the detection of $P$. multocida antibodies in sera was more sensitive when compared with other serological tests used for detection of antibodies against $P$. multocida. All the samples were screened by LPS based iELISA and have shown sensitivity of $\mathbf{9 1 . 0 4 \%}$, specificity of $\mathbf{9 6 . 4 1 \%}$ when compared with Indirect haemagglutination test. It was concluded that LPS could be useful antigen for detection of $P$. multocida antibodies in bovines.
\end{abstract}

Key words: Antibody, Haemorrhagic septicaemia, iELISA, Indirect haemagglutination, SDS-PAGE

Hemorrhagic septicaemia (HS) is acute highly fatal bacterial disease caused by gram negative bacteria Pasteurella multocida. The causative organism $\quad P$. multocida belonging to family Pasteurellaceae is grouped into five sero groups $\mathrm{A}, \mathrm{B}, \mathrm{D}, \mathrm{E}$ and $\mathrm{F}$ based on their capsular typing and (1-16) serotypes based on somatic typing (Harper et al., 2006). In India, HS is mostly caused by serotype B:2. It is one of the economically important livestock diseases with high mortality in many Asian countries. The disease has also been reported in 1974 in India.
According to the Indian epidemiological studies around 1974-1986, HS was placed first position in mortality rate compared with the other endemic diseases like FMD, anthrax and black quarter (Singh et al., 2014). P. multocida serotypes mainly occurs in bovines (cattle and buffalo) while septicaemic pasteurellosis recorded rarely or only sporadically in swine, camel, water buffaloes, poultry, horses, elephants, rabbits and other animals (Sarangi et al., 2014; Zhu et al., 2020). The HS is transmitted by direct contact with infected animals,

\footnotetext{
*Corresponding Author
} 
contaminated clothing, equipment, and through ingestion or inhalation of the organism. The clinical signs of the HS caused by serotype B:2 strain is characterized by fever, respiratory distress with nasal discharges and frothing from the mouth, leading eventually to leads to the death of the animal.

P. multocida serotype $\mathrm{B}: 2$ is a gram negative bacterium associated with HS has been found in Asia. The mechanism of the lipopolysaccharide, outer membrane proteins, etc. in virulence and protective immunity in effected animals has been described in various studies (Kharb and Charan, 2010; Wani et al., 2011). The lipopolysaccharides are the endotoxins that play a vital role in the pathogenesis of the disease. It induces many critical hurtful biological effects in the host. Endotoxins are also activating polymorph nuclear cells, monocytes and macrophages. A proper diagnosis is needed for the identification of the disease. Although several serological tests such as tube agglutination test, indirect haemagglutination, dot immunoblotting and enzyme linked immunosorbent assay (ELISA) for detecting antibodies against $P$. multocida used previously, none is universally accepted. In view of these facts, the present study was undertaken to develop lipopolysaccharide (LPS) based indirect enzyme-linked immunosorbent assay (iELISA) for the detection of $P$. multocida-specific antibodies in bovines. $P$. multocida lipopolysaccharide (LPS) has been used as an antigen for the detection of $P$. multocida antibodies in cattle and buffalos.

\section{MATERIALS AND METHODS}

Culture of $\boldsymbol{P}$. multocida and harvesting of culture: The lipopolysaccharide (LPS) antigen was extracted from $P$. multocida $\mathrm{B}: 2$ strain. For the extraction of LPS of $P$. multocida culture (MTCC1148) was grown overnight on BHI agar (Himedia, India).The bacterial cells ware harvested in normal saline and centrifuged at 8000 rpm for $10 \mathrm{~min}$. After centrifugation, bacterial pellet was used for LPS extraction.
LPS extraction and purification: LPS was extracted by modified hot phenol-water extraction method as described earlier (Zankharia, 2015). Approximate $12 \mathrm{~g}$ (wet weight) of bacterial pellet was suspended in $105 \mathrm{~mL}$ pre-warmed distilled water to $65-70^{\circ} \mathrm{C}$. After suspension of cells in water an equal volume of pre-warmed $65-70^{\circ} \mathrm{C}$, 90\% aqueous phenol (Fisher, India) was added to the cell suspension and the mixture was stirred vigorously at $65-70^{\circ} \mathrm{C}$ for $15 \mathrm{~min}$ followed by chilling on ice for $15 \mathrm{~min}$. The mixture was then centrifuged at $8000 \mathrm{rpm}$ at $4^{\circ} \mathrm{C}$ for $15 \mathrm{~min}$ for the separation of aqueous and phenol phases. After centrifugation upper aqueous phase (contains LPS) was collected and again the collected aqueous phase was centrifuged at $8000 \mathrm{rpm}$ for $15 \mathrm{~min}$ to remove insoluble impurities. Then the LPS was precipitated by adding $0.15 \mathrm{M}$ sodium acetate (Fisher, India) and 95\% ethanol (Merck) and sample was stored at $-20^{\circ} \mathrm{C}$ overnight in order to precipitate the LPS. Precipitates of LPS were collected by centrifugation at $5000 \mathrm{rpm}$ and the pellet was reconstituted in $2 \mathrm{~mL}$ distilled water. Sample was kept for dialysis against PBS at $4^{\circ} \mathrm{C}$ for $24 \mathrm{hrs}$ and collected LPS was stored at $4^{\circ} \mathrm{C}$. The purified LPS were used further as an antigen in immunoassays.

The purity of LPS was checked by running SDSPAGE and silver staining. SDS-PAGE was performed with discontinuous buffer system (SDSPAGE running buffur: $0.25 \mathrm{M}$ Tris, $1.92 \mathrm{M}$ glycine, $1 \%$ SDS); the LPS sample was mixed with $2 \mathrm{X}$ sample buffer and boiled for $5 \mathrm{~min}$. The electrophoresis was carried out with $12 \%$ resolving gel at $100 \mathrm{~mA}$ on gel electrophoretic apparatus (BioRad) with protein molecular weight marker (Spectra multicolour broad range protein ladder, Thermo Fisher Scientific, USA). Silver staining of the gel was performed according to the standardised protocol. The gel was fixed in fixation solution for 1 hour then renewed the fixation solution and kept for overnight incubation. The gel was sensitized in $10 \%$ tetrathionate solution for 45 minutes, then raised with $20 \%$ ethanol solution for thrice with 10 minutes of regular intervals along 
with 2 times gentle wash with distilled water. Then the gel was treated with silver nitrate solution for 30 minutes and washed with distilled water twice. The gel was developed with developer solution $(0.02 \%$ formaldehyde and $3 \%$ sodium carbonate) and reaction was stopped by adding stop solution (4\% w/v Tris and $2 \% \mathrm{v} / \mathrm{v}$ acetic acid). Then the developing gel was stored in fixation solution (Chevallet et al., 2006).

Sample collection: This study was conducted with approval from the Institutional Animal Ethics Committee of Genomix. A total 373 serum samples were randomly collected from dairy rearing households and local small dairy farms of Telangana and Rayalaseema region of Andhra Pradesh of India from July, 2018 to August, 2019 having no prior haemorrhagic septicaemia vaccination history. The blood samples were collected from jugular vein of each animal and serum was separated, stored at $-20^{\circ} \mathrm{C}$ for further use. The reference sera in this study were provided by the Department of Veterinary Public Health and Epidemiology, PVNR Telangana Veterinary University, Hyderabad.

\section{Development of Enzyme linked immunosorbent assay}

Optimization of ELISA assay: The optimization of working concentration of different reagents like LPS antigen, serum dilutions and conjugate in the assay was done by using checker board titration. The optimal concentration of the reagents cut-off values were calculated through screening and validation of the test with positive and negative control sera samples. Cut-off values were calculated by Percent positivity value, PPV=Total Positive / (Total Positive + False Negative) X 100

LPS concentration was estimated by commercial endotoxin estimation kit (Pierce Chromogenic Endotoxin Quantification Kit, Thermo Fisher Scientific). Then concentration was adjusted to $2 \mathrm{mg} / \mathrm{mL}$ by freeze drying. LPS antigen (150 $\mathrm{ng} /$ per well) was coated in each well of micro titre plate (Nunc) with coating buffer $(0.2 \mathrm{M}$
$\mathrm{Na}_{2} \mathrm{CO}_{3}$ and $0.2 \mathrm{M} \mathrm{NaHCO}_{3}$ ) (Fisher, India). Plates were incubated over night at $4{ }^{\circ} \mathrm{C}$. After incubation the plates were washed three times with wash buffer (1X PBS+Tween20) (Fisher, India). The plates were blocked with $6 \%$ skimmed milk powder (Amul, India) and incubated for 1 hour at $37^{\circ} \mathrm{C}$, after incubation plates were washed with wash buffer. The plates were dried under dehumidifier (Bryair, India). Once the plates were dried, they were packed with silica gels at $4^{\circ} \mathrm{C}$ till further use.

ELISA assay procedure: The test samples were diluted in a ratio of 1:100 in sample diluents buffer (1XPBS) along with controls i.e. known positive and negative serum samples in duplicates. Following $60 \mathrm{~min}$ incubation at $37^{\circ} \mathrm{C}$, the plates were washed three times in wash buffer (1X PBS+Tween20). The $100 \mu \mathrm{L}$ of Protein G HRP conjugate (1:10,000 diluted) (Sigma-Aldrich, USA) was added to each well and incubated for $60 \mathrm{~min}$ at $37^{\circ} \mathrm{C}$. After incubation, plates were washed and $100 \mu \mathrm{L}$ of TMB substrate (Abcam, USA) were added in each well and incubated in dark for $15 \mathrm{~min}$ or till the colour develops. Then the reaction was stopped with stop solution $(0.5 \mathrm{M}$ $\mathrm{H}_{2} \mathrm{SO}_{4}$ ) (Fisher, India). The absorbance was measured at $450 \mathrm{~nm}$ using an ELISA reader (Robonik, India).

Validation of the assay: Validation of the indirect ELISA was carried out by using 373 bovine serum samples with no history of vaccination and the assay was compared with the mostly used assay i.e., Indirect haemagglutination (IHA) test (El-Jakee et al., 2016). Briefly, overnight culture of $P$. multocida on BHI agar media was checked for its purity and the growth was harvested by washing the plates using $2-3 \mathrm{~mL}$ of $0.3 \%$ buffered formalin per plate. The capsular antigen of the bacterial suspension was separated by heat treatment at $60^{\circ} \mathrm{C}$ for 30 minutes followed by centrifugation at $2000 \mathrm{rpm}$ for 30 minutes and supernatant was collected. $0.1 \mathrm{~mL}$ of 5\% suspension of glutaraldehyde fixed sheep erythrocytes (Cho et al., 1976) were added, and the mixture was further incubated at $37^{\circ} \mathrm{C}$ for 
$30 \mathrm{~min}$. The sensitized erythrocytes were washed three times with phosphate-buffered saline by centrifugation and suspended in PBS containing $0.25 \%$ bovine serum albumin (BSAPBS). The IHA test was performed in U bottom plates by adding two-fold serial dilutions of antiserum made in BSA-PBS and $0.025 \mathrm{~mL}$ of the sensitized erythrocytes. The plates were shaken and allowed to stand for 1 to $2 \mathrm{~h}$ at $25^{\circ} \mathrm{C}$ before erythrocytes settling patterns were read. The IHA titer was expressed as the reciprocal of the highest dilution of serum showing a definite positive pattern (flat sediment), as compared with the pattern of the negative control (smooth dot in the centre of the well) (Qureshi and Saxena, 2014)

\section{RESULTS}

SDS-PAGE and silver staining: The concentration of the extracted LPS from P. multocida by phenolwater extraction method was around $2.08 \mathrm{mg} / \mathrm{mL}$. The SDS-PAGE of the water-phase LPS, reported pure LPS of 15KD molecular weight without any protein contamination (Fig. 1)

Validation of ELISA assay: The assay was optimized using purified LPS of P. multocida antigen. Out of total 373 test samples, 67 $(17.96 \%)$ were found positive for Pasteurella antibodies with iELISA whereas with IHA, 72 (19.30\%) samples were positive while 306 $(82.04 \%)$ were negative with iELISA while by IHA, $301(80.69 \%)$ were sero negative. The sensitivity and specificity of the iELISA were 91.04\% and $96.41 \%$, respectively (Table 1 ).

\section{DISCUSSION}

Haemorrhagic septicaemia caused by $P$. multocida serotype B:2 is the second most reported infectious disease of cattle and buffaloes in India and is the cause of major economic losses in livestock world. It is characterized by an acute and highly fatal septicaemia with high mortality rate $(60 \%)$ (Singh et al., 2014). The diagnosis of Pasteurella infection in livestock was important to take the preventive measures to control the spread of the disease immediately without any delay. The diagnosis of HS was mainly done by isolation of Pasteurella species but culture isolation is time consuming technique, the molecular detection was rapid and sensitive method but requires specialized laboratory personnel (Sinha et al., 2018). As a result, there is a need of rapid and reliable earlier identification of the bacterial infection in order to initiate appropriate antibiotic treatment at the earliest. There are few immunological assays available for the diagnosis of antibodies to the P. multocida. Rapid haemagglutination test is the most widelyused immunological assay for the diagnosis of HS disease. For accurate and appropriate disease diagnosis ELISA assay relatively robust and easier to perform, get the result quickly within 3 hours, affordable and, point of care testing format ELISA assay has been

Table 1. Sensitivity and specificity of iELISA for detection of $P$. multocida antibodies

\begin{tabular}{llccc}
\hline & & \multicolumn{3}{c}{ Indirect ELISA assay } \\
& & Positive result & Negative result & Total \\
\hline \multirow{2}{*}{$\begin{array}{l}\text { Indirect } \\
\text { haemagglutination }\end{array}$} & Positive result & 61 & 11 & $72(19.30 \%)$ \\
& Negative result & 6 & 295 & $301(80.69 \%)$ \\
& Total & $67(17.96 \%)$ & $306(82.04 \%)$ & \\
\cline { 2 - 5 } & Total samples: & & $\mathbf{3 7 3}$ \\
\hline
\end{tabular}

Sensitivity: $\mathrm{TP} /(\mathrm{TP}+\mathrm{FN}) \times 100$

Sensitivity: $91.04 \%$

Specificity: $\mathrm{TN} /(\mathrm{FP}+\mathrm{TN}) \times 100$

Specificity: $96.41 \%$ 
Indian Journal of Animal Health, June, 2020

LPS based iELISA detection of $P$. multocida antibodies

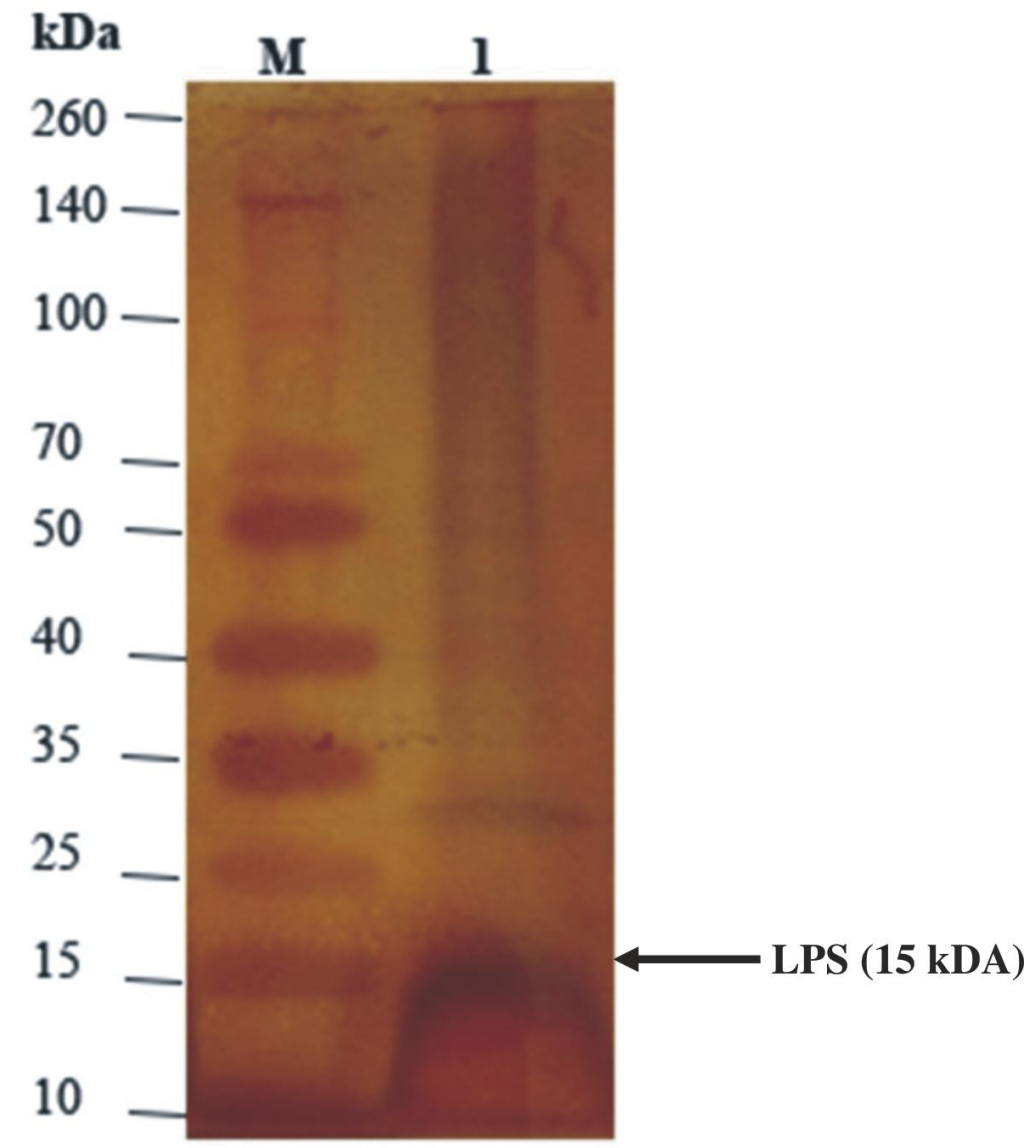

Lane M Molecular weight marker, 1 LPS from P. multocida

Fig. 1. SDS-PAGE/silver staining of LPS from $P$. multocida 
developing as important diagnostic technique for disease diagnosis and monitoring serological prevalence in animals against HS disease.

LPS is a major virulence factor of P. multocida (Harper and Boyce, 2017) and LPS is the most important bio-molecule present in the outer membrane of the $P$. multocida bacteria and having three distinct regions $\mathrm{O}$ antigen, core domain and lipid A. Lipid A part of the LPS is responsible for the toxicity also refer as endotoxin. This pathogenic nature of LPS causes systemic damage in the host. Besides LPS is also used for the detection of diseases as it induces innate immunity through toll like receptors (TLRs) (Farhana and Khan, 2020). According to the OIE Terrestrial Manual for Haemorrhagic Septicaemia (2018), the IHA assay as a tool to determine the antibody response in cattle. However, serological tests are not normally used for detecting antibodies or for disease diagnosis (OIE, 2018). Generally, haemorrhagic septicaemia is a disease that occurs mainly in farms that have poor biosafety or husbandry conditions. ELISA was recognized as a sensitive and accurate method and demonstrated to be able to detect the antibody against heat extracted antigen of P.multocida (El-Jakee et al., 2016; Tankaew et al., 2017) and ELISA can be used as best diagnostic assay than IHAT and Microtiter agglutination test (MAT) assays for the serological diagnosis of haemorrhagic septicaemia.

\section{REFERENCES}

Chevallet S, Luche S and Rabilloud T, 2006. Silver staining of proteins in polyacrylamide gels. Nat Protoc, 1(4): 1852-1858

Cho HJ, Ruhnke HL and Langford EV, 1976. The indirect hemagglutination test for the detection of antibodies in cattle naturally infected with mycoplasmas. Can J Comp Med, 40: 20-29

El-Jakee JK, Ali SS, El-Shafii SA, Hessian AM, AlArfaj AA et al., 2016. Comparative studies for serodiagnosis of haemorrhagic septicaemia in cattle sera. Saudi J Biol Sci, 23(1): 48-53
The aim of the present study was to develop an in-house indirect ELISA based on LPS for the detection of antibodies against to Pasteurella in bovines to identify disease natural or vaccination challenges, to screen the carrier animal which cause the spreading of infections and for the serosurveillance. In summary, an in-house indirect ELISA was successfully developed where LPS antigen of P. multocida (serovar B:2) as a coating antigen and Protein G HRP conjugate were used. LPS antigen at a concentration of $150 \mathrm{ng} / \mathrm{mL}$; sample serum at a dilution factor of 1:100 and Protein G-HRP in 1:10000 dilutions were optimal concentrations for the assay. In application, there were $17.96 \%$ (67/373) sera samples that were considered seropositive by the ELISA. This finding suggested that the iELISA can be used as a tool to detect the antibodies against haemorrhagic septicaemia in cattle in Indian context.

A sensitive and specific indirect ELISA based on LPS-antigen has been developed for the detection of $P$. multocida infection and the determination of the antibody titer against $P$. multocida in both cattle and buffaloes.

\section{Conflict of Interest: None}

\section{ACKNOWLEDGEMENTS}

The authors acknowledge the help received from the staff of Genomix group of companies.

Farhana A and Khan YS, 2020. Biochemistry, Lipopolysaccharide. In Statperals (Internet), Tresure Island (FL), Stat Perals Publishing, pp118

Harper M and Boyce JD, 2017. The myriad properties of Pasteurella multocida lipopolysaccharide. Toxins (Basel), 9(8): 254

Harper M, Boyce JD and Adler B, 2006. Pasteurella multocida pathogenesis: 125 years after Pasteur. FEMS Microbiol Letters, 265: 1-10

Kharb S and Charan S, 2010. Immunogenicity of iron- 
regulated outer membrane proteins of Pasteurella multocida B:2 in mice model. Indian J Exp Biol, 48(12): 1181-1187

OIE, 2018. OIE Terrestrial manual for haemorrhagic septicaemia, Chap 3.4.10, pp1133

Qureshi S and Saxena HM, 2014. Estimation of titers of antibody against Pasteurella multocida in cattle vaccinated with haemorrhagic septicaemia alum precipitated vaccine. Vet World, 7(4): 224-228

Sarangi LN, Priyadarshini A, Kumar S, Thomas P, Gupta SK et al., 2014. Virulence genotyping of Pasteurella multocida isolated from multiple hosts from India. Sci World J, 2014: 814109

Singh B, Shiv Prasad S, Verma MR and Sinha DK, 2014. Estimation of economic losses due to haemorrhagic septicaemia in cattle and buffaloes in India. Agric Econ Res Rev, 27: 271-279

Sinha RK, Kumari B and Kumar B, 2018. Haemorrhagic septicaemia in buffaloes and its therapeutic
management-A report of 3 Cases. Int J Curr Microbiol App Sci, 7: 2633-2636

Tankaew P, Singh-La T, Titaram C, Punyapornwittaya V, Vongchan P et al., 2017. Evaluation of an inhouse indirect ELISA for detection of antibody against haemorrhagic septicemia in Asian elephants. J Microbiol Methods, 134: 30-34

Wani MY, Goswami TK, Mir RA, Chaudhary D and Ram GC, 2011. Isolation, quantification and characterization of Pasteurella multocida Pm52 derived lipopolysaccharaide and its effect on nitric oxide production in mice. J Immunol Immunopathol, 13: 75-82

Zankharia US, 2015. Extraction, chararaterzation and determination of immunoreactivity of lipopolysaccharide of Salmonella Typhi. VNSGU J Sci Tech, 224-229

Zhu W, Fan Z, Qiu R, Chen L, Wei H et al., 2020. Characterization of Pasteurella multocida isolates from rabbits in China. Vet Microbiol, 244: 108649 